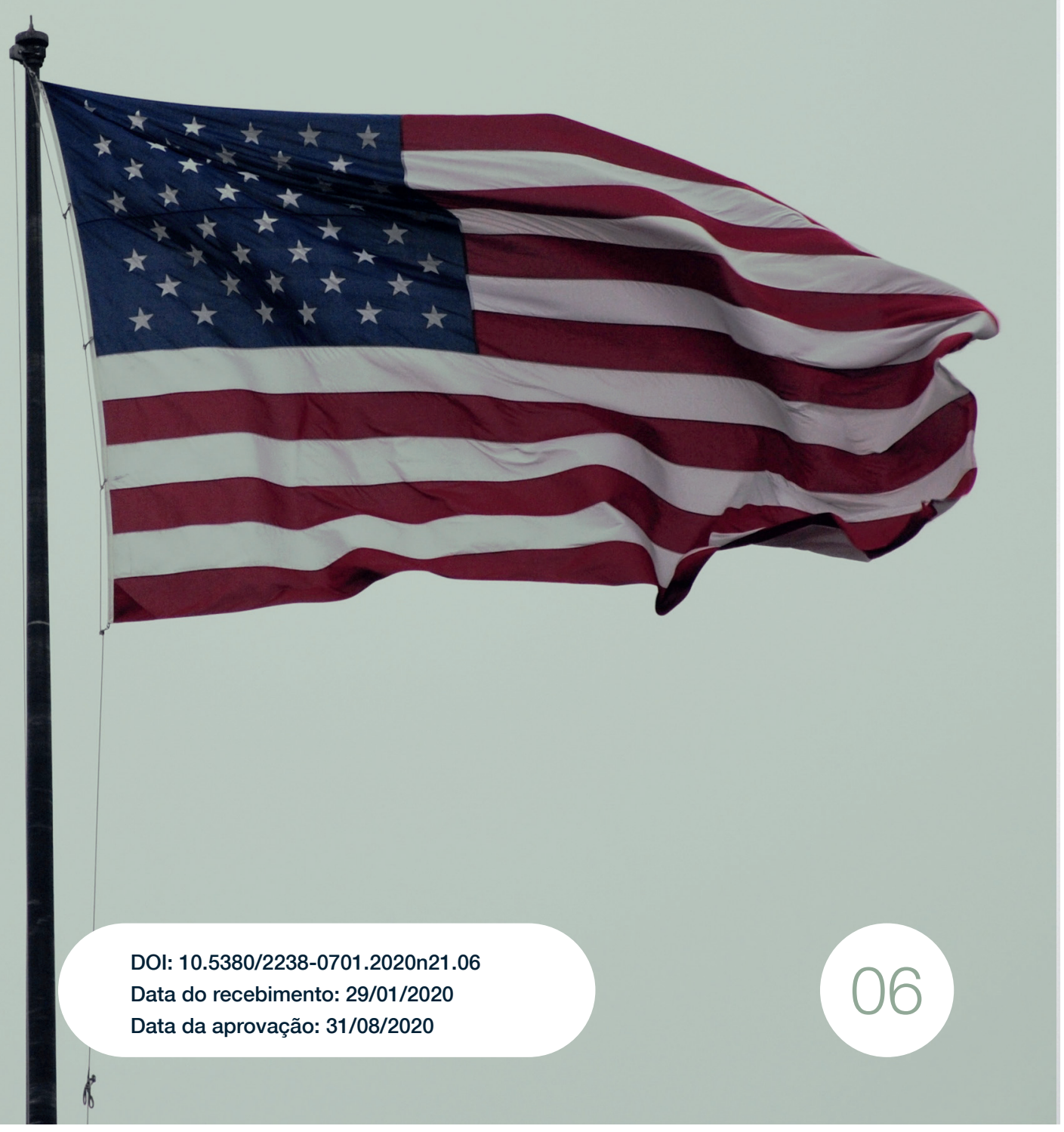


Da utopia democrática ao caos republicano: o lugar da ficção televisiva no reforço da (des)confiança nas instituições políticas estadunidenses 


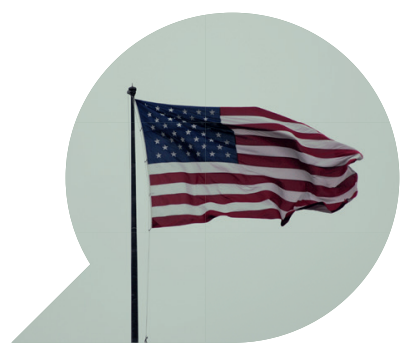

\section{Da utopia democrática ao caos republicano: o lugar da ficção televisiva no reforço da (des)confiança nas instituições políticas estadunidenses}

From a democratic utopia to republican chaos: the role of television's fiction in strengthening the (dis)trust in American political institutions

De la utopía democrática al caos republicano: el lugar de la ficción televisiva en el fortalecimiento de la (des) confianza en las instituciones políticas estadounidenses

\begin{tabular}{c}
\hline MELINA MEIMARIDIS $^{1}$ \\
\hline RODRIGO QUINAN $^{2}$ \\
\hline
\end{tabular}

Resumo: $\mathrm{O}$ artigo teoriza sobre as instituições ficcionais nas séries televisivas estadunidenses e o papel desempenhado por elas na construção dos imaginários associados às instituições do mundo real. Utilizando um viés sociológico, realiza-se uma análise comparativa das narrativas dos dramas políticos The West Wing e

\footnotetext{
1 Doutoranda do Programa de Pós-Graduação em Comunicação da Universidade Federal Fluminense, onde concluiu seu mestrado. Se graduou com Láurea Acadêmica, em Estudos de Mídia pela supracitada Universidade. Coordenou o Série Clube, projeto acadêmico e colaborativo dedicado à investigação e ao debate de aspectos relativos à linguagem da ficção seriada televisiva entre 2012-2018. 2 Mestre e doutorando pelo Programa de Pós-Graduação em Comunicação pela Universidade Federal Fluminense, onde concluiu sua graduação em Estudos de Mídia. Tem experiência docente na graduação em Estudos de Mídia da UFF, como parte das atividades de estágio docência do mestrado.
} 
House of Cards. Identificou-se que, enquanto a primeira constrói uma visão funcional das instituições políticas, a segunda as apresenta de forma desmoralizada e enfraquecida. A hipótese central é que essas produções atuam no processo de reforço da (des) confiança para com as instituições que compõem o sistema político republicano dos Estados Unidos.

Palavras-chave: Televisão; Séries; Instituições sociais ficcionais; Construção social da realidade.

Abstract: The article theorizes about fictional institutions in American television series and the role they play in the construction of the imaginary associated with real-world institutions. A comparative analysis of the narrative of the political dramas The West Wing and House of Cards is performed through sociological lenses. It was identified that while the first builds a functional view of political institutions, the second presents them as demoralized and weakened. The central hypothesis is that these productions act in the processes of reinforcing (dis)trust with the institutions that make up the republican political system in the United States.

Keywords: Television; Series; Fictional social institutions; Social construction of reality.

Resumen: Este artículo teoriza sobre las instituciones fictícias en las series de televisión estadounidenses y el papel que desempeñan en la construción del imaginario asociado a las instituciones del mundo real. A través de una perspectiva sociológica es realizado un análisis comparativo de la narrativa de los dramas políticos The West Wing y House of Cards. Se identificó que mientras el primero construye una visión funcional de las instituciones políticas, el segundo las presenta como desmoralizadas y debilitadas. La hipótesis central es que estas producciones actúan en los procesos de refuerzo de la (des)confianza hacia las instituciones que conforman el sistema político republicano en los Estados Unidos.

Palabras-clave: Televisión; Serie; Instituciones sociales fictícias; Construcción social de la realidad. 


\section{Introdução}

Durante sua visita a Myanmar, a então secretária de Estado do governo estadunidense Hillary Clinton se espantou com o relato do presidente da Câmara dos Comuns sobre os parlamentares do país estarem consumindo episódios de The West Wing (NBC, 1999-2006) como uma forma de "aprender a ser um congresso democrático"3 (tradução nossa). Este uso peculiar de um drama ficcional político causou estranhamento, principalmente por causa da dicotomia que separa a ficção da informação e, de maneira mais geral, da realidade. Tradicionalmente, a ficção tem sido enquadrada como muito distante do mundo real e, portanto, não suficientemente capaz de influenciá-la. Porém, a linha que separa a ficção da realidade é mais permeável do que se pensou inicialmente. Este artigo sustenta que a ficção pode ser considerada sociologicamente uma realidade, sendo capaz de exercer funções estruturadoras do real. Aqui, argumentamos que neste processo as séries televisivas são capazes de naturalizar certo sentido de ordem ou caos. Mas como elas fazem isso?

Em linhas gerais, é por meio da ficcionalização de instituições sociais que isso acontece. As séries retratam o funcionamento diário de diversas instituições sociais, como os hospitais, os tribunais e a família. Contudo, o modo como elas fazem isso tem sido pouco explorado pela literatura acadêmica. Na sua maior parte, os trabalhos existentes focam nas séries a partir de uma perspectiva instrumental - por exemplo, a sua capacidade de disseminar conteúdo educativo (BEAVERS, 2002; MUR$\mathrm{PHY}$, et al. 2012) - ou do ponto de vista da forma como representam as instituições em função da sua fidelidade à realidade social (MALMSHEIMER, 1988; STARK, 1987). Alternativamente, este trabalho explora a ideia de que as instituições sociais ficcionalizadas servem de base para um discurso e suas expectativas acerca do funcionamento destas instituições do mundo real. À luz da discussão sobre construção social da realidade (BERGER; LUCKMANN, 1991 [1966]) e de sua aplicação ao campo da comunicação (ADONI; MANE, 1984; COULDRY; HEPP, 2017), objetivamos compreender como as instituições sociais da ficção contribuem na construção dos imaginários associados a essas entidades sociais na vida real.

3 Disponível em: <https://bit.ly/33yQDOP>. 
A questão específica que nos interessa explorar aqui diz respeito à coexistência de duas perspectivas antagônicas de representação das instituições pelas séries: a funcional e a disfuncional. No primeiro caso, as séries apresentam as instituições cumprindo essencialmente as expectativas de ordenamento do mundo social atribuídas a elas: médicos salvam pessoas; políticos atuam com vistas ao interesse público, policiais resolvem crimes. No segundo caso, o foco principal recai sobre as falhas e ambiguidades morais dos personagens e os dilemas que entravam a eficiência dessas organizações no cotidiano. Para ilustrar o ponto, o artigo compara o modo como as instituições políticas estadunidenses são representadas em The West Wing e em House of Cards (Netflix, 2013-2018). Enquanto a primeira constrói uma visão funcional e quase utópica das instituições políticas, a segunda as apresenta como corruptas, enfrentando crises e colapso moral.

\section{O lugar da ficção na construção social da realidade}

Séries institucionais são pouco contempladas por estudos acadêmicos. Contudo, em termos concretos, elas desempenham um papel essencial na ecologia televisiva estadunidense. Elas são usualmente muito populares: 18 das 20 séries mais assistidas na fall season de 2019-20204 são institucionais, e longevas, algumas, como Law \& Order SVU (NBC, 1999-) se estendem por mais de duas décadas. Além disso, as instituições sociais concretas, como o Pentágono (ROBB, 2004), o Departamento de Defesa (MARTIN, 2019), a CIA (JENKINS, 2016) e a American Medical Association (TUROW, 2010), reconhecem a ficção televisiva como um importante espaço de autoridade e de construção de sentido, fazendo investimentos consideráveis para controlar os discursos ficcionais produzidos acerca delas mesmas.

Para dar conta do modo como as instituições ficcionais referenciam a experiência social, o artigo adota a perspectiva de Construção Social da Realidade, inicialmente proposta por Berger e Luckmann (1991). Eles propõem que o nosso acesso à realidade é necessariamente mediado por nossas experiências subjetivas e pelas definições intersubjetivas que compartilhamos com aqueles que nos cercam. Em especial, as ins-

4 Disponível em: <https://bit.ly/3imHSgS>. 
tituições desempenham um papel fundamental no processo de objetificação da vida social, visto que elas "controlam a conduta humana estabelecendo padrões predefinidos de conduta" (BERGER \& LUCKMANN 1991, p.72, tradução nossa). Dessa maneira, essas organizações não definem somente como as coisas são, mas também como devem ser. Esse processo abrange diversos segmentos da vida social. Ao mesmo tempo, reconhecemos que as instituições sociais estão relacionadas às rotinas, estabelecem os objetivos a serem conquistados e as formas adequadas para atingi-los. Couldry e Hepp (2017) ressaltam o papel das instituições no ordenamento do cotidiano quando afirmam que "as características específicas e (relativamente) estáveis do mundo social em que vivemos fazem parte da construção que as instituições se esforçam para sustentar, no contexto de um fluxo mais complexo e incerto de possíveis estados do mundo social" ( p. 27, tradução nossa).

Entretanto, Giddens (1991) propõe que as instituições têm se distanciado da tradição, que tinha a função de reforçar nos sujeitos a segurança de que as coisas são como são porque sempre foram assim. Para o autor, após diversas mudanças na sociedade, se modificaram também as relações humanas, que deixaram de ser essencialmente interações face-a-face para se tornarem interações dependentes e mediadas por sistemas de confiança. Segundo ele, as instituições sociais modernas sofrem de um ''deslocamento' das relações sociais de contextos locais de interação e sua reestruturação através de extensões indefinidas de tempo-espaço" (GIDDENS, 1991, p.24), que o autor denomina de "desencaixe". Dentre os mecanismos de "desencaixe", destaca-se o conceito de sistema perito, que é definido como "sistemas de excelência técnica ou competência profissional que organizam grandes áreas dos ambientes material e social em que vivemos hoje" (GIDDENS, 1991, p.35). Esses sistemas organizam inúmeros aspectos do mundo material e social. Um exemplo são os sistemas que envolvem profissionais com conhecimento especializado, como os advogados, médicos, engenheiros, entre outros. Fundamentalmente, é desses sistemas peritos que tratam as séries institucionais. Embora Giddens, Berger e Luckmann não tenham focado na mídia como elemento central do processo de construção da realidade, outros autores dão a ela um papel de destaque (ADONI; MANE, 1984; SILVERSTONE, 1994; COULDRY; HEPPS, 2017). 


\section{As instituições sociais ficcionais}

Entendemos aqui que as séries institucionais são centradas em sistemas de competência especializada, como, por exemplo, a ciência forense em CSI (CBS, 2000-2015), o judiciário em The Good Wife (CBS, 2009-2016), a medicina em ER (NBC, 1994-2009) e as instituições políticas em Parks and Recreation (NBC, 2009-2015). Essas produções apresentam as ações e os procedimentos da rotina diária dos profissionais associados a essas instituições. Todas essas esferas de poder são apresentadas como dependentes do conhecimento dos peritos (médicos, juízes, policiais, cientistas, advogados, etc.) e, em alternativa, os sistemas peritos são dependentes da confiança dos sujeitos no conhecimento de seus especialistas. De acordo com Giddens (1991), essa confiança ou fé é o que impede os indivíduos de estarem constantemente em estado de insegurança. A confiança e seu reforço são, portanto, elementos fundamentais na continuidade da vida moderna. Entretanto, "há um elemento pragmático na fé, baseado na experiência de que tais sistemas geralmente funcionam como se espera que eles o façam" ( $p$. 36). Assim, são necessários mecanismos que reforçam a confiança e a autoridade dos peritos, lembrando os indivíduos do funcionamento das instituições sociais.

Aqui, consideramos que as séries institucionais cumprem este papel ao apresentar rotineiramente rituais, jargões, códigos de conduta, procedimentos e até normas éticas implementadas por meio de diversas instituições sociais ficcionais. O drama médico Grey's Anatomy (ABC, 2005-), por exemplo, apresenta semanalmente um grupo de médicos que se envolve em um caso diferente e demanda que os profissionais executem determinadas rotinas de trabalho, como examinar e preparar um paciente para cirurgia, operar um paciente, debater com outros médicos possíveis tratamentos, dentre tantas outras tarefas específicas do trabalho de um cirurgião. Dessa forma, Grey's Anatomy tanto historiciza as instituições médicas ao mostrar de forma padronizada as ações que as compõem, como lembram aos indivíduos sobre os papéis desempenhados por estas instituições.

Embora a maioria das séries institucionais tenha na construção da confiança o seu ponto de ancoragem, desde a década de 1980 que um número crescente de produções passou a explorar as instituições do 
ponto de vista da sua disfuncionalidade. Exemplos pioneiros incluem o drama policial Hill St. Blues (NBC, 1981-1987) e o drama médico St. Elsewhere (NBC, 1982-1988), e, mais recentemente, The Shield (FX, 20022008), centrada na corrupção policial, e The Knick (Cinemax, 20142015), que destaca os limites do conhecimento médico em um hospital no início do século XX. Essas séries estão relacionadas a um momento maior de desconfiança generalizada vis-à-vis as instituições e ao governo estadunidense, ocorrido após o escândalo do Watergate 5 e o fim da Guerra do Vietnã (1955-1975) (JACOBS, 2002). Ambas as produções dos anos 1980 dramatizavam embates profissionais frente às ambições mais burocráticas e mundanas das instituições.

\section{Workplace dramas e ficções presidenciais}

Com a vitória capitalista na Guerra Fria e a consolidação de um modelo neoliberal que aproximou grande parte dos empregos ao setor corporativo, dramas situados em ambientes de trabalho ascenderam ao topo da televisão estadunidense a partir dos anos 1990. Se na década anterior séries como Hill St. Blues, L.A Law (NBC, 1986-1994) e St Elsewhere já desfrutavam de bons números de audiência e celebrada atenção crítica, novas produções, como a recordista em longevidade Law \& $\operatorname{Order}$ (NBC, 1990-2010) e ER, donas das maiores audiências estadunidenses da década, abriram caminho para os workplace dramas se firmarem como produções essenciais. Com dezenas de séries bem-sucedidas situadas em espaços médicos, judiciais e policiais, não tardaria para instituições políticas também serem exploradas.

Diversas instâncias governamentais já foram apresentadas nas séries desde a esfera local, como a câmara dos vereadores em Parks and Recreation, passando pelas esferas estaduais, como o escritório da procuradoria e o governo estadual em The Good Wife, até as esferas federais do escritório da vice-presidente em VEEP (HBO, 2012-2019) e da secretária do estado em Madam Secretary (CBS, 2014-2019). Dada a natureza complexa das instituições políticas, muitas destas séries não

5 Escândalo político ocorrido no início da década de 1970 em que o presidente Richard Nixon foi acusado de ter envolvimento no assalto ao Comitê Nacional Democrata. $\bigcirc$ escândalo culminou com a renúncia do presidente. 
só apresentavam essas organizações, como também revelavam as relações do governo com outros setores da sociedade, como a imprensa, a polícia, o crime e o judiciário. Tendo em vista esta multiplicidade de produções, optamos por analisar apenas dois dramas políticos que consideramos centrais para o formato: The West Wing, que levou a tradição de workplace dramas da emissora NBC à Casa Branca, e House of Cards, produção original da Netflix. Embora atendendo as peculiaridades das diferentes formas de distribuição, ambas as séries são dramas que se utilizaram do melodrama e de custosa produção cinematográfica para reivindicar autoridade sobre o real.

\section{1. $O$ reforço da confiança em The West Wing}

Provavelmente o drama político mais bem-sucedido da história da televisão estadunidense, The West Wing estreou em 1999, criado pelo comentado produtor Aaron Sorkin, durando sete temporadas e 156 episódios. A série segue o mandato do presidente democrata ficcional Josiah Bartlet (Martin Sheen), acompanhado por seus assessores e situado na movimentada ala oeste da Casa Branca, que dá o nome à série. Altamente aclamada, a produção desfrutou de grande audiência, abrangendo cerca de 17 milhões de lares na sua segunda temporada ${ }^{6}$. Recordista de vitórias consecutivas no Emmy Awards, a série usufruía de uma reputação erudita ao ter uma audiência com renda e graus de escolaridade mais altos do que os demais dramas ficcionais da época ${ }^{7}$. Dona de uma elaborada cinematografia, notavelmente lembrada por sequências de assessores andando e falando em corredores da Casa Branca ("walk and talk"), o drama agrupava semanalmente diferentes enredos que incluíam desde questões políticas tratadas pela administração, até tópicos do ambiente de trabalho ou da vida pessoal dos seus personagens.

Em profundo contraste com o retrato negativo e vigilante realizado pelo jornalismo estadunidense na mesma época (SOUKUP, 2002), The West Wing apresentava uma visão romântica e idealizada do funciona-

6 Disponível em: <https://eonli.ne/2skjcdD>.

7 The West Wing era a única série no ar em 2001 cuja a renda anual da audiência ultrapassava \$70.000, segundo Spitzer (2001). Disponível em: <http://bit.ly/2RvG096 >. 
mento das instituições políticas do país. Recentemente abalados por escândalos sexuais que culminaram em um julgamento de impeachment do então presidente Bill Clinton, os estadunidenses buscavam alívio (LEVINE, 2003) no contraste oferecido pelo presidente Bartlet, que era um íntegro administrador e dedicado homem da família. Favorecendo discussões liberais, a série ainda encontrou novo significado após a eleição do republicano George Bush em 2000, chegando a ser categorizada como uma fantasia onde os conservadores não ganharam as eleições (GANS-BORISKIN; TISINGER, 2005), embora, após os atentados de 11 de Setembro, a série tenha se alinhado precisamente às políticas da Guerra ao Terror levantadas pelo governo Bush.

The West Wing apresentava temas complexos como armamentismo, epidemia da AIDS, racismo, distribuição de renda e democracia, mostrando eventos e acontecimentos como eleições, ataques terroristas e guerras; estes tópicos eram debatidos pelos personagens da série de forma íntegra, mesmo as mais ferozes discordâncias sendo baseadas em intenções nobres por um bem maior. No mundo da série, o mal deliberado é uma ocorrência rara, com mesmo os mais graves deslizes de seus personagens sendo representados como erros honestos, cometidos por idealistas passionais ou articulações políticas bem intencionadas. A instituição política, portanto, é apresentada de forma funcional e reguladora quando ocorre alguma ação desviante.

Mais central que a representação política da série era o seu retrato de um ambiente de trabalho funcional. Convidando a identificação das audiências com seus próprios espaços profissionais ao preencher detaIhados cenários com intensa atividade de extras e figurantes (BEAVERS, 2002), The West Wing recriava os corredores da Casa Branca para abrigar figuras como o assessor Joss Lyman (Bradley Whitford), o diretor de comunicações Sam Seaborn (Rob Lowe), a assessora de imprensa CJ Cregg (Allison Janney), o escritor de discursos Toby Ziegler (Richard Schiff), o chefe de governo Leo McGarry (John Spencer), a secretária Donna Moss (Janel Moloney) e a figura paterna de todos que era representada pelo presidente Bartlet. A relação desses personagens era desenvolvida de forma delicada, com grande ênfase nos fortes laços de lealdade, amizade e pertencimento criados entre os funcionários pelos episódios, bem como o bem-sucedido entrosamento profissional entre eles. A ideia de intimidade era também reforçada pela relação próxima 
do staff com a família do presidente Bartlet, que, quando necessário, também se envolvia em questões pessoais dos seus assessores.

Seja nas relações políticas, profissionais ou pessoais, o grande mantra da série era o bom caráter, principalmente no que se refere aos profissionais que povoavam a Casa Branca. Nas incansáveis noites de trabaIho, constantemente era a implacável integridade dos personagens que encontrava soluções na narrativa (HOLBERT, 2003), com atalhos controversos ou acordos corruptos virtualmente inexistentes no âmbito moral dos protagonistas. Esta perspectiva utópica gerou reações opostas de críticos e acadêmicos. O otimismo foi visto como positiva alternativa ao jornalismo agressivamente movido a escândalos, com o tom provocativo da série sendo visto como de valor pedagógico (BEAVERS, 2002) para o debate público sobre os temas levantados. Por outro lado, o tom fantasioso da narrativa foi acusado de criar percepções equivocadas do funcionamento da política estadunidense, afastar o enredo de problemas reais e promover uma visão parcial a favor do governo democrata, reforçando práticas de uma parcela liberal mais privilegiada e elitista.

Como na vida real, os democratas da série também apoiaram massivamente a Guerra ao Terror, com o governo democrata ficcional do drama, após o 11 de setembro, ecoando muito da postura do governo republicano de George Bush no mundo real. Na sua terceira temporada, que foi ao ar logo após os atentados, a série endossou a visão de que o terrorismo é fruto do ódio fundamentalista pela "liberdade e pluralidade" dos Estados Unidos ("Isaac \& Ishmael', episódio especial não-numerado), propondo intervenção internacional estadunidense como solução (GANS-BORISKIN; TISINGER, 2005).

Desta forma, seja apresentando uma realidade alternativa de sucesso democrata, ou reforçando valores ocidentais de um governo republicano, The West Wing exibe um Estados Unidos com instituições políticas incontestavelmente sólidas, com profissionais íntegros, virtuosos e extremamente dedicados por trás do funcionamento delas, sempre procurando criar um governo para todos os estadunidenses, nunca antagonizando conservadores o suficiente para tirá-los do quadro de forma polarizante, ainda que a preferência seja por ideais liberais. Bartlet, por alguns anos, tinha maior popularidade que Clinton ou Bush (HOLBERT, 2003). A fantasia da série penetrou imaginários e dialogou com políticas do mundo real: a série termina com a eleição de Matt Santos (Jimmy 
Smits), presidente minoritário eleito como sucessor de Bartlet: Eli Attie, então roteirista da série, admitiu que os roteiristas moldaram o personagem calcado no então jovem senador Barack Obama ${ }^{8}$, também de minoria étnica, que dois anos depois seria similarmente eleito para a Casa Branca.

Temos, então, The West Wing no ar em dois períodos políticos diferentes: as primeiras temporadas da série propõem um presidente clintonesco (FRITZ, 2015), mas sem os expostos escândalos de Bill Clinton que marcaram o período, e o segundo período da série se torna consolo para a vitória republicana em 2000, construindo um universo paralelo onde democratas ainda estão no poder. Há ainda um terceiro momento, identificável após o término da série: sem obter números oficiais dos serviços, um artigo do The New York Times aponta que a produção, remasterizada e disponibilizada por serviços de streaming, tem sido revisitada em larga escala nas novas plataformas ${ }^{9}$. Em um período onde Trump ignora expectativas operacionais das instituições, The West Wing remete a um meio termo ideal, em que a relação entre liberais e conservadores é mais harmoniosa e políticos obedecem a um conjunto de normas esperado por pessoas públicas naquelas funções. A ênfase no funcionamento institucional associado a série culminou em uma reunião especial às vésperas das eleições estadunidenses de 2020, onde o elenco e convidados como Michelle Obama e Bill Clinton enfatizaram a importância da participação popular no processo democrático ${ }^{10}$.

\section{O reforço da desconfiança em House of Cards}

Se podemos descrever The West Wing como uma utopia democrática em que as instituições políticas funcionam plenamente, House of

\footnotetext{
8 Disponível em: <http://bit.ly/2Rcoftl>.

9 Disponível em: <https://nyti.ms/39MuQYt>.

10 Lançado 27 outubro de 2020, duas semanas antes das eleições presidenciais de 2020, The West Wing Special to Benefit When We All Vote reuniu o elenco para uma reencenação teatral do episódio Hartsfield's Landing $(03 \times 14)$, contando também com manifestos dos atores e de figuras como Michelle Obama, Bill Clinton, Samuel L Jackson e Lin-Manuel Miranda sobre a importância do voto, esclarecimentos sobre o processo democrático e alertas sobre desinformação e supressão de votos, estratégias notáveis da campanha de Trump. O especial foi feito em apoio a organização sem fins lucrativos When We All Vote, lançada para conscientizar estadunidenses da importância da participação no processo democrático.
} 
Cards, por sua vez, é uma representação cínica do sistema político republicano em que os atores que compõem a instituição são moralmente ambíguos, muitas vezes motivados por seus próprios interesses, ganâncias e ambições profissionais. A produção é uma adaptação de um drama político britânico da BBC One, que foi exibido na década de 1990. A versão estadunidense foi criada por Beau Willimon, contava com os atores renomados Kevin Spacey e Robin Wright como os protagonistas da série e o célebre diretor David Fincher, que dirigiu os dois primeiros episódios. O drama teve seis temporadas e 73 episódios. O arco principal da narrativa se manteve inicialmente intacto, no entanto, as histórias dos personagens secundários foram aprofundadas na adaptação.

A produção começa acompanhando o personagem de Spacey, Frank Underwood, um deputado do partido Democrata e sua esposa Claire na cerimônia de posse do novo presidente dos Estados Unidos. Durante a cerimônia, Underwood, olhando para a câmera, inicia um monólogo em que apresenta o universo sujo da política em Washington. A quebra da quarta parede é uma marca estilística da série e é utilizada recorrentemente pelos protagonistas. O recurso permite que Frank e Claire compartilhem suas tramas, inquietações e até debochem de adversários com os espectadores, formando, assim, uma certa relação de cumplicidade. A série começa quando, a despeito de toda a inteligência de Frank, seus planos para se tornar Secretário de Estado não se concretizam. O cargo lhe havia sido prometido pelo presidente, que ele ajudou a ser eleito. Com esta traição, Underwood começa um novo esquema de manipulação, colocando determinadas peças em movimento (jornalistas, deputados, assessores, lobistas) para que formem seu plano maior, tanto de vingança contra aqueles que o traíram, quanto de ascensão de poder ao tão ambicionado cargo de Presidente dos Estados Unidos.

Reconhecemos que Frank compartilha diversas características com outros anti-heróis que povoaram a televisão durante a chamada terceira era de ouro, em produções como The Sopranos (HBO, 1999-2007) e Breaking Bad (AMC, 2008-2013). Frank é carismático, possui uma inteligência maquiavélica e é moralmente ambíguo. Todas características importantes do arquétipo do anti-herói (MITTEL, 2015), que recorre a homens brancos, de meia idade, detentores de algum poder institucional ou função patriarcal. Francis, ao ser acusado de mentir, apenas afirma que mentir é "o mesmo que fazer política" ("Chapter 4", 1x04), deixando 
subentendido que seus desvios morais não são traços exclusivos da sua personalidade e, sim, uma postura obrigatória para sobrevivência no jogo político. Nenhuma ação é imoral demais para Underwood, que chantageia, ameaça e até se envolve no assassinato de outros políticos e jornalistas. Frank expõe aos espectadores toda a manipulação e negociações que acontecem "por debaixo dos panos" em Washington.

Assim, a série apresenta um cenário político tenebroso quase inteiramente desprovido de caráter e idealismo. A produção, dessa forma, não narra apenas os planos imorais e egoístas de um anti-herói (como, por exemplo, a jornada individual por enriquecimento de Walter White, interpretado pelo ator Bryan Cranston, em Breaking Bad), mas, sim, apresenta um cenário de completa desmoralização das instituições políticas, com a grande maioria dos personagens sendo agentes independentes e despreocupados com o bem-estar da população que os elegeu, sempre abertos à possibilidade da corrupção para alcançar suas ambições. O personagem de Doug Stamper (Michael Kelly) está à disposição de Underwood para executar seus planos imorais, enquanto que Claire, por sua vez, também tem um caráter duvidoso. A personagem, após a renúncia de Frank ao cargo de presidente dos Estados Unidos no final da quinta temporada e sua intempestiva morte no início da sexta temporada, assume o cargo se tornando a protagonista da série ${ }^{11}$.

No universo de House of Cards, as teorias da conspiração são reais, com a série produzindo enredos que materializam ficcionalmente teorias circuladas nas mídias sociais, dialogando diretamente com tensões epistemológicas do mundo real. Notavelmente, a morte do funcionário público democrata Seth Rich permeia o imaginário da quinta temporada da série. Morto a tiros em um assalto em 2016, Rich teve seu nome veiculado em diversas teorias da conspiração ligadas a grupos de direita, sugerindo o envolvimento de forças superiores democratas, entre elas o também casal de poderosos presidenciáveis Bill e Hillary Clinton. Na série, o governo igualmente recorre a assassinato de políticos que ameaçam o projeto de poder dos protagonistas ("Chapter 11", 1x11; "Chapter 64", 5x12); a obra ficcional também discorre sobre imaginários de outras teorias da conspiração, como operações terroristas bandeira-falsa, sob interesse de avançar a agenda política e econômica de representantes

11 A mudança de protagonista não foi apenas uma escolha narrativa, mas, sim, ocorreu após Kevin Spacey ser demitido pela Netflix após acusações de abuso sexual surgiram contra o ator. Para mais informações, ver: <http://bit.ly/38\|HvO2>. 
estadunidenses ("Chapter 52", 4x13), a incriminação e o assassinato de jornalistas considerados "problemáticos" para abafar suspeitas ("Chapter 14", 2x01; "Chapter 19", 2x06), o uso de tecnologia e da mineração de dados para fraudar eleições ("Chapter 72", 6x07), dentre outras.

No entanto, o diálogo mais direto com a cultura das teorias da conspiração é a representação da democracia de modo completamente disfuncional. O governo estadunidense é apresentado como brutal, recorrente a quaisquer meios ilegais para beneficiar políticos, sempre corrupto e centrado nos seus próprios interesses. A série sublinha as fragilidades da democracia estadunidense quando Francis e Claire chegam à presidência sem terem sido eleitos diretamente pelo voto popular dos cidadãos para o cargo ("Chapter Twenty-six", 2x13 e "Chapter Fifty-eight', 5x13, respectivamente).

É importante também notar o clima político favorável para a criação de uma narrativa carregada de desconfiança em instituições governamentais. Estreando em 2013, a série se afasta do patriotismo exacerbado de produções que estiveram no ar durante os atentados de 11 de setembro e a Guerra Ao Terror. Em 2013, o país estava sob problemas econômicos após uma recente recessão, a desilusão com o presidente Obama, que, apesar de reeleito, se afastava das calorosas promessas de reformas sociais prometidas na campanha de 2008, e a ascensão de movimentos neoconservadores, que propagavam centenas de teorias da conspiração contra o governo, futuramente essenciais na eleição de Trump.

Contudo, não são apenas as instituições políticas que estão desmoralizadas no universo narrativo de House of Cards. A série também revela o relacionamento escuso dos políticos com a mídia. Os políticos tentam controlar os ciclos das notícias e, para isso se utilizam de fatos, fofocas, desinformação e até mentiras estrategicamente divulgadas à imprensa. Frank se aproveita de sua influência política para controlar e gerenciar os escândalos políticos de forma anônima. A ambiciosa e jovem jornalista Zoe Barns (Kate Mara) o conhece no primeiro episódio da série e se relaciona profissional e sexualmente com Underwood para conseguir acesso às informações privilegiadas. No entanto, enquanto Zoe acredita que está avançando em sua carreira, a personagem está, de fato, conduzindo a agenda de poder de Underwood. Por meio dela a série dramatiza a atual crise que o jornalismo vem enfrentando no século 
XXI. A produção constrói uma oposição entre os profissionais mais experientes do jornal "The Washington Herald" - que possuem uma visão mais próxima do jornalismo investigativo tradicional e defendem ideais do modelo de jornalismo estadunidense, como a objetividade (SCHUDSON, 2010 [1978]), a checagem de fatos e os passos e procedimentos regulados pela instituição para garantir a imparcialidade jornalística e Zoe, que se interessa mais pelas subjetividades da vida política de Washington e considera a morosidade dos processos jornalísticos "antiquados" no mundo das mídias sociais e do jornalismo digital, mesmo que isso signifique abrir mão dos ideais do jornalismo (BOUTET, 2015).

\section{Discussão}

Observamos ao longo de nossa análise que The West Wing e House of Cards apresentam uma visão privilegiada dos bastidores do poder na arena política estadunidense. Essas produções revelam as manobras políticas e jogos de poder que envolvem não só instituições políticas, mas, também, as instituições da mídia e do judiciário em Washington. O processo de ficcionalizção das instituições sociais representadas, no entanto, é distinto em cada série. A leitura da contrastante representação política entre as séries deve ser realizada diretamente nas tradições televisivas que constroem a fundação de ambas. Como um workplace drama veiculado na NBC (TV aberta), The West Wing dá continuidade a uma crescente e bem-sucedida tradição do formato em construir representações ficcionais sobre instituições e locais de trabalho, com ênfase em como coletivos funcionam a favor da sociedade. Neste tipo de narrativa, a individualidade é tratada em segundo plano. Já House of Cards dialoga com tradições televisivas mais contemporâneas. A Netflix replicou o formato temático e estrutural das séries de anti-heróis, construindo sua narrativa política de uma íntima e extensa análise de um indivíduo. Underwood, virtuoso caucasiano de meia idade, ocupa o centro da produção, com grandes instituições políticas que espelham o mundo real servindo muitas vezes apenas de ferramentas para pôr em práticas as virtudes excepcionais, mesmo que moralmente ambíguas, do personagem, que manipula, trama e conspira para ascender ao topo do poder.

Isto posto, The West Wing é uma série sobre uma instituição excep- 
cional, a ala oeste da Casa Branca, e House of Cards, sobre um indivíduo excepcional, Frank Underwood. Outros personagens, como Claire e Zoe, igualmente são mostradas como agentes independentes, afastadas das suas instituições mesmo quando empregadas nelas. Esta dicotomia reflete dois interesses culturais em dois momentos diferentes do capitalismo neoliberal (o espaço de trabalho versus o poderoso empreendedor individual), dois diferentes formatos televisivos (workplace drama versus drama de anti-herói) e especialmente dois veículos de transmissão que operam sob normas diferentes, com a NBC obrigada a produzir um conteúdo de baixo risco para anunciantes, enquanto a Netflix, apoiada por uma base de assinantes, tem liberdade para produzir conteúdo mais ousado e sem compromisso com questões morais.

No que se refere à forma como cada produção apresenta processos técnicos que no mundo burocrático real despertam pouco interesse popular, identificamos que ambas as séries historicizam as funções de deputados, senadores, chefes de gabinetes, ministros e dos próprios presidente e vice-presidente dos Estados Unidos. Os dois dramas políticos representam as funções desses funcionários públicos e os empecilhos aos seus trabalhos como governantes da nação. Para isso essas séries apresentam a expertise desses personagens e o regimento interno das instituições políticas estadunidenses.

Tomemos como exemplo o processo de aprovação de uma nova legislação. No episódio "Five Votes Down" (1x03) de The West Wing, o presidente Bartlet anuncia que está prestes a realizar uma importante promessa de sua administração ao aprovar uma legislação antiarmamentista. Entretanto, na véspera da votação, os assessores do presidente descobrem que a emenda não tem o número de votos necessários no congresso. Os assessores, então, começam a negociar com os deputados, buscando alianças, oferecendo subsídios e isenções legais de impostos. Nesse processo, os membros do partido democrata buscam atrapalhar a legislação, ameaçando seus membros de represálias partidárias caso votem contra o partido e o presidente. O episódio se encerra com o vice-presidente John Hoynes (Tim Matheson) conseguindo os votos e sendo apresentado pela mídia como o grande herói da noite. A agenda por trás do político é revelada em um diálogo interno: conquistar a presidência. Mesmo configurado como vilão, a estratégia política de Hoynes é traçada pelo jogo político de forma legítima e pautada no seu idealismo. 
Já em House of Cards, no episódio "Chapter 16" (2x03), o governo democrata, ameaçado por um shutdown (quando ocorre um congelamento das verbas federais), opta por negociar com os senadores republicanos a aprovação orçamentária em troca de uma lei que eleva a idade mínima da aposentadoria, questão que o partido republicano ficcional e real ${ }^{12}$ busca aprovar há décadas. A estratégia do vice-presidente Frank Underwood é fazer com que o Senado, com maioria republicana, aprove o acordo para que o presidente possa anuncia-lo em seu discurso anual no State of the Union. Os democratas precisam que dez republicanos se abstenham ou que cinco votem a favor da lei, ou alguma outra combinação desses dois cenários apresentados aos espectadores por meio da fala dos assessores do vice-presidente. Após oferecer verbas distritais para senadores republicanos, Underwood consegue garantir os votos. Contudo, senadores republicanos contrários se articulam e abandonam o senado antes que se forme um quórum. Frank, então, assume seu lugar como presidente do Senado e demanda que o sargento de armas traga de volta os senadores, que retornam algemados e carregados pelos guardas. Com um quórum, os democratas conseguem aprovar a legislação. A cena lembra um evento similar que ocorreu no senado estadunidense em $1988^{13}$.

Dadas as devidas proporções, ambas as produções apresentam o funcionamento da política estadunidense em que os governantes precisam do apoio dos deputados e dos senadores para o bom funcionamento do governo. Em ambos os casos, os representantes do presidente têm que negociar com congressistas e senadores em troca de apoio para aprovação da nova legislação. Contudo, as negociações de The West Wing aparentam ser mais burocráticas, enquanto que, em House of Cards, o voto dos senadores é apresentado como moeda de barganha, guiado por seus próprios interesses. Observamos em ambas as séries como os personagens se esforçam para tirar proveito da lei e usá-la a seu favor, sem necessariamente estarem quebrando leis e/ou violando a constituição. No caso de House of Cards, destacamos como a série apresenta a importância da expertise no campo político, com Underwood vencendo os senadores republicanos ao se utilizar das normas e do próprio regimento interno do senado. O domínio do saber no campo 
político é recorrentemente apresentado na série como um diferencial do personagem.

Evidenciamos que The West Wing se centra na ação de políticos e funcionários públicos bem-intencionados que são convocados a superar as dificuldades e armadilhas da arena política estadunidense. Já House of Cards, explora as fragilidades desse sistema e como os protagonistas tiram proveito dessas fraquezas. As séries lidam, portanto, de formas distintas com a questão da responsabilidade institucional e das consequências encaradas por indivíduos desviantes. Quando The West Wing apresenta profissionais que cometem erros, são negligentes ou agem de forma antiética, eles sofrem consequências, são suspensos, perdem seus empregos ou cargos políticos. Alternativamente, em House of Cards, são poucas as consequências que os personagens ambíguos sofrem, enquanto que os idealistas são apresentados como não-dominantes do saber político e frequentemente sofrem na mão dos protagonistas. Assim, a maioria dos políticos da série são apresentados como corruptos e os que não são geralmente são destruídos por aqueles que são.

A despeito dos membros comprometidos de The West Wing, as instituições estão funcionando plenamente e têm mecanismos de controle para impedir os abusos dos profissionais "desviantes". Torna-se dever dos agentes da instituição combater esses indivíduos e restabelecer a ordem institucional. Contudo, nesse processo, The West Wing desloca a responsabilidade da instituição, colocando-a sobre o indivíduo. Neste sentido, não é o sistema político que é falho, mas alguns políticos que são responsáveis por corrompê-lo. Diferentemente, House of Cards apresenta um cenário em que as instituições estão enfraquecidas e os protagonistas não só tiram proveito, como escapam da regulação institucional.

Em nossa análise encontramos, porém, que as séries televisivas podem construir visões distintas de instituições sociais ficcionais em uma mesma produção. Em House of Cards, a despeito do caos associado às instituições políticas, a série ainda reforça certo ordenamento das instituições da mídia, principalmente no que se refere ao papel dessas instituições na manutenção da natureza democrática das instituições políticas. Dessa maneira, a produção endossa uma visão tradicional do jornalismo "independente" como um importante agente de accountability, que 
vigia os governantes e divulga seus excessos à população. Na série, enquanto Zoe é facilmente manipulada por Underwood, Janine e Lucas se mostram menos influenciáveis, dedicando-se a suas investigações sobre a corrupção governamental. Este fato demonstra a dificuldade de se analisar as instituições sociais ficcionais como organizações isoladas. Como as instituições sociais do mundo real, as ficcionais se relacionam entre si e têm seus sentidos construídos por meio de um processo complexo que envolve diversas instituições, seus agentes e a sociedade de maneira geral.

Encerramos, então, indicando que cada uma das representações da realidade política estadunidense aponta para um momento epistemológico diferente: o idealismo quase fantasioso de The West Wing, no ar em um período de conforto econômico para a classe média estadunidense, que remete a um momento de credibilidade institucional característico da segunda metade do século XX, com o retrato de um governo confiável, dono de autoridade pouco contestada, mesmo quando a série normaliza perigosas práticas estadunidenses, como o patriotismo, o imperialismo e o intervencionismo internacional. Já House of Cards, escrita poucos anos após a grave recessão de 2008, representa um período mais recente de crise epistemológica, no qual a integridade de instituições públicas é altamente contestada. A série valida desconfiança e paranoia contra instituições, como a política e a mídia, sempre corrompidas a favor de poderosos agentes ocultos, legitimando, assim, conteúdo antiepistemológico do mundo real, algo também exemplificado na ficcionalização de teorias da conspiração, que levam a série a reproduzir uma postura anti-institucional, também presente nos movimentos extremistas que vêm ganhando espaço nos últimos anos.

Estudos futuros deverão analisar os dois modelos apresentados neste artigo, tanto isoladamente, quanto em conjunto, levando em consideração os contextos em que essas séries foram exibidas. As séries televisivas de maneira geral, e as institucionais em particular, então, se provam como significativos espaços de construção de sentido sobre a realidade. 


\section{REFERÊNCIAS}

ADONI, H.; MANE, S. Media and the social construction of reality: Toward an integration of theory and research. Communication research, v. 11, n. 3, p. 323-340, 1984.

BEAVERS, S. L. The West Wing as a Pedagogical Tool. The West Wing: The American Presidency as Television Drama. Ed: Peter Rollins and John O'Connor. Syracuse: Syracuse. UP, 2002. 175-86

BERGER, P. L.; LUCKMANN, T. The social construction of reality: A treatise in the sociology of knowledge. Penguin UK, 1991.

BOUTET, M. The politics of time in House of Cards. In DÄWES, Birgit; GANSER, Alexandra. Transgressive Television: Politics and Crime in 21st-Century American TV Series, pp. 83-102, Heidelberg: Universitätsverlag Winter, 2015.

COULDRY, N.; HEPP, A. The mediated construction of reality. Cambridge: Polity Press, 2018.

FRITZ, A. J. M. The West Wing and House of Cards: A Comparison of Narrative Strategies of Two Politically-themed Dramas. Colloquy. Vol 11, Fall 2015. pp: 126-152

GANS-BORISKIN, R.; TISINGER, R. The Bushlet Administration: Terrorism and War on The West Wing. The Journal of American Culture. Theme Issue. Volume 28, Number 1. March 2005.

GIDDENS, A. As consequências da modernidade. São Paulo: Editora da UNESP, 1991a.

HOLBERT, R. L. et al. The West Wing as Endorsement of the U.S Presidency: Expanding the Bounds of Priming in Political Communication. Journal of Communication, September 2003.

JACOBS, J. 'Hospital Drama', In CREEBER, G. (Ed.) The Television Genre Book, London: British Film Institute, p. 23-6, 2002.

JENKINS, T. The CIA in Hollywood: how the agency shapes film and television. University of Texas Press, 2016.

LEVINE, M. A. The West Wing (NBC) and the West Wing (D.C): Myth and Reality in television portrait of the White House. In: P.C Rollins, \& J.E O'Connor (Eds.), The West Wing: The American Presidency as Television Drama. (pp. 42-62). New York, NY. Syracuse University Press. 2003

MALMSHEIMER, R. Doctors Only: The Evolving Image of the American Physician, Nova lorque, Greenwood Press, p. 26-39, 1988.

MARTIN, S. J. Imagineering empire: how Hollywood and the US national security state 'operationalizes narrative'. Media, Culture \& Society, p.1-16, online first, 2019.

MITTELL, J. Lengthy interactions with hideous men: Walter White and the serial poetics of television anti-heroes. In: Storytelling in the media convergence age. Palgrave Macmillan, London, 2015. p. 74-92.

MURPHY, S. T. et al. Public diplomacy in prime time: Exploring the potential of entertainment education in international public diplomacy. American journal of media psychology, v. 5, n. 1-4, p. 5, 2012.

ROBB, D. L. Operation Hollywood: How the Pentagon shapes and censors the movies. Prometheus Books, 2004.

SCHUDSON, M. Descobrindo a notícia: uma história social dos jornais nos Estados Unidos. Petrópolis: Vozes, 2010. 
SOUKUP, C. Television viewing as vicarious resistance: The X-Files and conspiracy discourse, Southern Communication Journal, 68:1, 14-26. 2002.

STARK, S. D. Perry Mason meets Sonny Crockett: The history of lawyers and the police as television heroes. University of Miami Law Review, v. 42, p. 229, 1987.

SILVERSTONE, R. Television and Everyday Life. Routledge, 1994.

TUROW, J. Playing Doctor. New York: Oxford University Press, 2010.

Data do recebimento: 29 janeiro 2020

Data da aprovação: 31 agosto 2020 


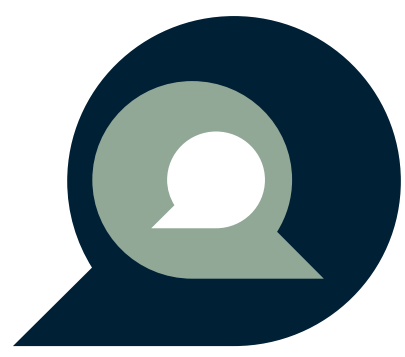

